\title{
Configurações
}

Revista de sociologia

$9 \mid 2012$

Trabalho e género: vidas precárias, percursos e acção colectiva

\section{Precariedade, sindicalismo e ação coletiva}

Precariousness, trade unionism and collective Action

Précarité, syndicalisme et action collective

\section{Elísio Estanque}

\section{(2) OpenEdition}

Journals

\section{Edição electrónica}

URL: http://journals.openedition.org/configuracoes/1133

DOI: $10.4000 /$ configuracoes. 1133

ISSN: 2182-7419

\section{Editora}

Centro de Investigação em Ciências Sociais

\section{Edição impressa}

Data de publição: 30 Junho 2012

Paginação: 81-102

ISSN: 1646-5075

Refêrencia eletrónica

Elísio Estanque, « Precariedade, sindicalismo e ação coletiva », Configurações [Online], 9 | 2012, posto online no dia 27 novembro 2013, consultado o 30 abril 2019. URL : http://journals.openedition.org/ configuracoes/1133; DOI : 10.4000/configuracoes.1133

Este documento foi criado de forma automática no dia 30 Abril 2019

(c) CICS 


\title{
Precariedade, sindicalismo e ação coletiva
}

\author{
Precariousness, trade unionism and collective Action \\ Précarité, syndicalisme et action collective
}

Elísio Estanque

\section{NOTA DO AUTOR}

Uma versão semelhante deste artigo foi publicada no Brasil, sob o título "Informalidades, precariedades e ação colectiva", in Roberto Véras de Oliveira; Darcilene Gomes; Ivan Targino (orgs.) Marchas e contramarchas da informalidade do trabalho: das origens às novas abordagens, Recife: Editora Massangana, 2011. Agradeço a Dora Fonseca o trabalho de levantamento efectuado na caracterização dos movimentos de combate à precariedade, que serão referidos na parte final.

\section{Introdução}

Os impactos da globalização dos mercados e das políticas neoliberais sobre o mercado de trabalho têm sido a diversos títulos devastadores, atingindo todos os continentes. As condições de trabalho alteraram -se profundamente nas últimas décadas, embora, evidentemente, cada região evolua no quadro de características muito particulares. Não se trata, portanto, de um processo linear e muito menos homogéneo, inclusive quando nos referimos ao contexto europeu. Na Europa, a questão da precariedade ganhou novos contornos e intensificou -se substancialmente com a chegada do novo milénio perante o aumento de formas de assalariamento e vínculos contratuais, perante a expansão do que então se chamou "trabalho atípico". Ulrich Beck (2000) tinha -se referido a essa tendência como uma "brasileirização do Ocidente", ou seja, quando o fim do fordismo e a crise do Estado-Providência davam mostras de esgotamento e parecia inevitável um processo de 
flexibilização e de imparável "emagrecimento", à custa da retirada de direitos e conquistas que antes foram concebidas como irreversíveis.

2 Na verdade, o que antes foi designado como trabalho "atípico" - referente a actividades de grande dureza e sem proteç̧ão, formas de subcontratação, empregos em part-time, situações de ilegalidade que atingiam sobretudo certas minorias como os jovens recém entrados no mercado de trabalho, as minorias étnicas e migrantes, as mulheres sem qualificação, os trabalhadores a tempo parcial, os clandestinos, etc. - começou a generalizar-se e, como sabemos, os vínculos contratuais a termo certo, os trabalhadores em empresas de trabalho temporário, os falsos recibos verdes e várias outras formas mistas de precariedade do trabalhador e de negação dos seus direitos atingem hoje amplas camadas da força de trabalho, com especial incidência sobre os mais jovens. 0 que antes era considerado "atípico" tornou-se entretanto um novo padrão. Estamos a assistir a uma corrosão, em larga escala, das instituições e a um preocupante recuo do Estado social sob o pretexto da sua urgente "reforma".

3 Na esfera laboral, em particular, a contratação coletiva e todo um edifício protector do trabalhador está em risco de desmoronar-se, perante a impotência dos cidadãos e das próprias estruturas representativas dos trabalhadores. Enquanto os poderes e interesses económicos privados nos empurram para uma crise cada vez mais aguda e de consequências imprevisíveis, o direito do trabalho é ignorado e insiste -se na receita neoliberal somando à austeridade a total flexibilização de despedimentos, mesmo sabendo que tal contraria a Lei fundamental da República.

4 Num momento em que o edifício social das democracias europeias evidencia tanta fragilidade, importa recorrer aos instrumentos teóricos e analíticos da sociologia para questionar os factores de coesão social e interpelar alguns dos seus principais protagonistas. Importa, portanto, discutir o campo laboral e o papel do sindicalismo à luz do seu significado e do papel que lhes compete no quadro mais geral do sistema democrático. É nesse sentido que a presente reflexão assume o pressuposto de que o trabalho não é apenas uma atividade económica e produtiva, mas, mais do que isso, é o principal elo de ligação entre o indivíduo e a sociedade, pelo que as estruturas organizadas do sindicalismo representam um capital precioso (que hoje está sob ameaça de esgotamento).

5 Tendo como pano de fundo estas preocupações, procurarei discutir alguns dos problemas que o mundo sindical português enfrenta hoje, quer perante as dificuldades decorrentes do cenário sociolaboral que acabei de referir, quer também porque começam a surgir outras formas de denúncia e de acção especificamente vocacionadas para responder aos problemas dos segmentos mais precarizados da força de trabalho.

Importa, pois, compreender os sinais emergentes na esfera produtiva e sindical. Esse é o objetivo principal deste texto. As perplexidades que se colocam a este respeito não deixam antever soluções viáveis no imediato pelo que convém deixar em aberto - não nos resta, aliás, outra alternativa - as respostas quanto ao desfecho da actual crise. Serão os sindicatos e estruturas federativas capazes de organizar o crescente contingente de trabalhadores precários na Europa? Faz sentido esperar uma possível renovação do campo sindical de modo a ampliar e intensificar as suas formas de intervenção? Estarão os seus líderes em condições de estabelecer aproximações e alianças com os novos movimentos que estão a emergir do campo laboral? Qual o papel dos novos meios 
informáticos e do chamado "ciberativismo" em todo este processo, que se pretende de viragem rumo à consolidação democrática e dos direitos de cidadania no trabalho?

\section{Precariedade, regulação e ação}

7 A precariedade não é senão a expressão mais direta de uma realidade concreta que retira segurança e direitos de protecção ao trabalhador assalariado. Porém, a precariedade tem subsistido e tem -se insinuado desde há décadas, mesmo em setores do emprego onde existem leis claras que a pretendem combater. A tão criticada "rigidez" das leis laborais têm convivido com expedientes e práticas extremamente flexíveis e muitas vezes ilegais, com todo o rol de abusos e prepotências de todo o tipo. Em sectores industriais tão exemplares como o do calçado, por exemplo, há muito que foram apontadas diversas situações onde a precariedade - e até o medo - são realidades indesmentíveis (Estanque, 2000).

8 Em sentido sociológico, pode dizer-se que o informal é o que está antes, depois, e nos interstícios do institucional. Entre a sociedade e o direito há permanentes tensões e conexões, pelo que, mais do que a descoincidência entre a law in books e a law in action importa realçar a inelutável primazia da praxis sobre a normatividade da lei. Seja no plano político, seja no cultural ou no económico, o informal escapa à norma oficial, ou, se quisermos, opõe-lhe uma dimensão outra, que obedece mais à lógica das relações de poder do que ao correspondente enquadramento jurídico.

9 Enquanto o campo do formal é da ordem da regulação e da reprodução, o campo informal procura resistir ou ir além do statu quo estabelecido. Todavia, a recusa de uma normatividade particular contém o gérmen da nova normatividade a instituir no lugar da velha. Se é nos subterrâneos da informalidade que as instituições e a ordem dominante podem ser minadas e subvertidas, também é verdade que a legalidade pode constituir um instrumento de mudança progressista.

Nas sociedades democráticas ocidentais - em especial na Europa -, o potencial emancipatório do aparelho jurídico foi inúmeras vezes posto à prova desde o período do pós guerra. O próprio "contrato social", edificado desde o século XIX, em resultado de uma sucessão de convulsões sociais e de um amplo debate filosófico, sobretudo com a expansão do Iluminismo (e o contributo especial de figuras como T. Hobbes, J. Locke, Montesquieu, J. -J. Rousseau, etc.), deu lugar a um vasto conjunto de medidas e direitos cívicos que ajudaram a uma progressiva emancipação das classes laboriosas. Direitos que, como se sabe, hoje estão sob ameaça na Europa, cedendo o passo ao novo mercantilismo do século XXI.

11 As leis em favor dos mais fracos tornaram -se uma arma da justiça social, mas elas nunca foram sufi cientemente fortes para se tornarem irreversíveis. Resultado das lutas operárias, não deixaram de refletir o compromisso capital -trabalho, reflexo da correlação de forças entre as duas classes antagónicas numa época em que a combatividade operária permanecia vigorosa. Mas, esse compromisso só se perpetuou enquanto foi útil à consolidação do capitalismo, favorecendo a harmonia social e a ordem estabelecida. Nas últimas décadas, na Europa, reforçou-se de novo o elo mais forte da relação capital-trabalho, e o compromisso foi rasgado. Sob o pretexto da sustentabilidade, o Estado social europeu está sendo desmantelado, porque as suas instituições e políticas de solidariedade se tornaram dispendiosas e os mecanismos de regulação - com o direito 
do trabalho à cabeça - deixaram de responder às exigências de acumulação lucrativa, ditadas pelo neoliberalismo e pelos interesses do capital financeiro. A economia especulativa desdobrou-se em múltiplas formas e os antigos defensores do Estado social passaram a subvertê-lo e procuram agora construir uma nova harmonia fundada no retrocesso (Silva, 2009).

É precisamente este o quadro onde se inscrevem as novas dinâmicas laborais que se vêm expandindo à escala global desde a viragem do milénio. Os excessos do capitalismo liberal, que na Europa e no ocidente haviam sido travados pela regulação estatal, vêem-se agora livres dos antigos constrangimentos. Cresceram livremente, transcendendo os limites impostos pela ação institucional e pelos estados nacionais e vêm promovendo e reinventando novas formas de informalidade laboral, criando mais dependências e formas opressivas sobre a classe trabalhadora.

13 A atual tendência de precarização das relações de trabalho, de dissociação entre condições profissionais e vínculos laborais, está de facto a pôr em causa os velhos critérios e formas de diálogo, os valores de solidariedade e, no fundo, o modelo de contrato social inspirado pela filosofia iluminista e consolidado desde o pós-guerra. Não é demais sublinhar que nos últimos vinte anos as transformações ocorridas do mercado de trabalho fustigaram de forma dramática os direitos e a qualidade do emprego. 0 modelo produtivo, que até aos anos oitenta do século passado pôde sustentar uma classe média que parecia em expansão, sofreu entretanto convulsões profundas que abalaram abruptamente as suas expectativas mais risonhas. $\mathrm{O}$ aumento e a diversificação da precariedade laboral passou a constituir um dos principais traços de recomposição do mercado de trabalho, tanto em Portugal, como nos outros países da União Europeia. Vimos assistindo a uma "tendência que traduz o estilhaçar da homogeneização e estabilidade em que assentava o padrão modal do emprego, quanto à natureza do vínculo laboral, ao tempo de trabalho e ao estatuto social do trabalhador" (Gonçalves, 2010: 184).

Na última década, os postos de trabalho em regime de contratos permanentes diminuíram ao mesmo ritmo em que aumentaram os contratos a termo certo. Aliás, o crescimento das situações precárias - ou o que outrora se designava como situações "atípicas" no campo do emprego - têm evoluído para uma profunda alteração do velho padrão de estabilidade, obedecendo hoje a uma multiplicação de situações e de percursos profissionais, bem como no plano subjetivo e das vivências, quer do emprego quer do desemprego, numa reconfiguração permanente, que justifica novos questionamentos sobre essas novas formas de prestação de trabalho que podem designar -se de novas "patologias da democracia laboral" (Ferreira, 2009: 76). Os valores do emprego precário (se somarmos os contratos a termo, os recibos verdes, os trabalhadores temporários e o trabalho a tempo parcial) aproximam -se já dos 28 a 30\% do emprego. Este tipo de contratos aumentou progressivamente e em todas as faixas etárias, sendo a referida geração (hoje popularizada pelo nome de Geração à Rasca) ${ }^{1}$ a que mais sofre com isso, o que acontece, de resto, em muitos países europeus como, por exemplo, a Espanha, a Alemanha, a Suécia e a França onde, tal como em Portugal, mais de $50 \%$ dos trabalhadores desta geração já se encontram em situação precária (Gonçalves, 2010). 0 desemprego de jovens licenciados tem vindo a agravar -se nos últimos anos, atingido os 55 mil casos (em 2010), embora se saiba - e convém realçá-lo - que os licenciados auferem salários mais elevados e permanecem menos tempo em situação de desemprego ou de trabalho precário. Em todo o caso, quer o desemprego quer os contratos não permanentes atingem especialmente o segmento mais jovem. E isso aconteceu de forma drástica, estando $37,6 \%$ dos 
trabalhadores com idades entre 15 a 34 em situação laboral de contratos a prazo, e considerando apenas o segmento etário dos 15 aos 24 anos, essa percentagem já se aproximava em 2010 dos 50\% (INE, 2007, Inquérito ao Emprego; Carmo, 2010).

No caso português e dos países do sul da Europa (para falar apenas da segunda metade do século $\mathrm{XX}$ ) a tardia industrialização, aliada às experiências traumáticas de Estados ditatoriais (que duraram décadas) impediram que uns e outros - instituições e movimentos - pudessem fluir e acompanhar as tendências dos países mais avançados, inclusive impedindo que o sindicalismo autónomo se consolidasse e cumprisse o seu papel transformador. Nestas condições, a cultura autoritária e tutelar exercida pelo Estado Novo, escudada no subconsciente coletivo, continuou a insinuar -se junto dos principais mentores do edifício democrático (partidos políticos incluídos), desse modo minando e subvertendo o processo de consolidação da cidadania politica e social (não obstante toda a retórica revolucionária e de esquerda que dominou esse período).

É possível então considerar que em Portugal se assistiu a uma "compressão do tempo histórico" que no espaço de uma década (1975 a 1986) produziu um Estado social - ou um quasi Estado Providência, como lhe chamou Boaventura Sousa Santos - e um quadro institucional e jurídico tão avançado como o das sólidas democracias europeias, mas paradoxalmente criou as condições para a sua negação. Dito de outra maneira, o formalismo da legislação e da própria Constituição (de orientação "socialista", aprovada em 1976), parecem ter sido criados apenas para fi car no papel ou, pior ainda, para ornamentar o discurso político da época, partilhado, aliás, por um vasto leque de partidos políticos (da esquerda à direita).

\section{Ação, estrutura e movimentos sociais}

17 Isto leva -nos a sublinhar a ideia da descoincidência entre quadros legais e práticas sociais, ou seja, a recordar o principio sociológico de que a realidade do social se inscreve no plano da cultura, dos valores e do subconsciente, mais do que na consciência dos atores sociais. Estes, sendo embora dotados de racionalidade e de consciência, essa racionalidade é limitada por uma complexidade de factores produzidos pelo sistemas de ação concreta onde se inserem, cujas relações de "poder paralelo" repousam mais nos "bastidores" da informalidade do que no "palco" das relações sociais. $O$ ator e o sistema estão mutuamente imbricados. Não existe uma determinação de um sobre o outro, mas antes um processo dinâmico de recriação permanente e recíproco. Se as zonas de imprevisibilidade e de incerteza refletem o jogo de poderes entre ação e estrutura, entre o micro e o macro, é das conexões recíprocas que se estabelecem entre essas diversas instâncias que emergem as condições da ação coletiva.

18 Convém, pois, situar a génese da ação nas zonas mais recônditas da sociedade e não necessariamente nas instituições. Estas, agem, legitimam, normalizam e consolidam os equilíbrios e consensos resultantes de negociações e conflitos - latentes ou manifestos entre as forças no terreno. Daí que a capacidade transformadora resida mais na fase de emergência e consolidação de um movimento do que quando este dá lugar a um novo enquadramento formal e institucional. Podemos pensar o próprio sindicalismo como o culminar de um longo processo em que essa dupla vertente (movimento/ instituição) desde sempre evidenciou as tensões entre duas lógicas tão contraditórias. Por outro lado, também no plano económico - sendo este indissociável da sociedade e da política, como bem têm evidenciado as novas correntes teóricas da economia política (Stiglitz, 2004; 
Louçã e Caldas, 2009; Reis, 2009) - poderemos identificar o mesmo contraste entre racionalidade e identidade, ambas dimensões inerentes à atividade produtiva.

Antes de continuar a reflexão sobre a precariedade, convirá situar, ainda que brevemente, as condições de emergência da classe operária inglesa do século XIX, tendo em vista recordar alguns dos principais traços do sindicalismo dessa época. Esta referência justifica -se, não para repetir aquilo que de há muito a história e as ciências sociais deram a conhecer, mas pela necessidade de ensaia uma leitura mais atualizada do fenómeno, tendo em vista a análise prospectiva das atuais modalidades de ação coletiva no campo laboral e sindical. Com efeito, mesmo quando o foco da análise se dirige à Europa, é necessário olhar o tempo presente identificando nele elementos suscetíveis de comparação com o período de emergência do moderno capitalismo industrial. Se é verdade que a história vivida não se pode apagar, também, como se sabe, o passado não se limita a uma acumulação de acontecimentos factuais. Compreender o passado é sempre um exercício de memória que se presta a sucessivas reinterpretações, sendo estas inevitavelmente condicionadas pela realidade presente. E sabemos bem o quanto as atuais tendências da sociedade capitalista nos têm obrigado a reler o passado e a questionar algumas das narrativas sobre o mesmo, até há pouco consideradas verdades inquestionáveis (Tilly, 1978; Skocpol, 1985; Savage, 2004).

Os movimentos sociais constituem de facto experiências decisivas de ação (por vezes de grande impacto), na transformação social e política das sociedades, e o caso do movimento operário constituiu, na verdade, uma resposta às condições degradantes em que foi colocado o operariado enquanto nova classe assalariada nascida da Revolução Industrial. O movimento operário, por exemplo, emergiu, justamente, de um conjunto de convulsões que marcaram a Europa da era moderna, nas quais assumiu central importância a componente cultural e identitária.

21 É claro que foram, em primeiro lugar, as duras condições socioeconómicas impostas pelo capitalismo selvagem que fizeram emergir o operariado como classe. Porém, o nascimento da working class em Inglaterra derivou não apenas da realidade económica strictu senso, antes forjou -se da fusão entre identidades comunitárias e identidades de classe, num quadro de relativa dispersão e sob a influência de ambientes culturais específicos. Ou seja, a classe operária não surgiu, como por vezes se pensa, animada fundamentalmente por objectivos progressistas, revolucionários ou emancipatórios mas, em boa medida, a partir de lutas desencadeadas em nome da defesa da comunidade e muitas vezes contra a inovação técnica, como foi o caso do movimento ludista (Thompson, 1987; Savage, 2004).

Um dos principais estudiosos dos movimentos sociais chamou a atenção de que nem a resistência dos trabalhadores à inovação e ao progresso técnico nem a dimensão meramente reivindicativa da acção sindical exprimem a existência de um movimento social. Para Alain Touraine, "não há movimento social enquanto os operários se opuserem à industrialização e partirem as máquinas ou resistirem às novas técnicas... Para que se torne movimento social é necessário que fale em nome dos valores da sociedade industrial e se torne defensor dos mesmos contra os seus próprios adversários" (Touraine, 1994: 285). Assim, um movimento social só existe quando uma dada luta colectiva obedece aos princípios de (i) identidade: uma comunidade mobilizada e animada por um sentimento de pertença; (ii) oposição: a existência de um adversário comum, claramente identificado; (iii) totalidade: com objetivos sociais mais vastos e apoiado por um projeto cultural alternativo (Touraine, 1984; Dibben, 2004). 
23 Se o movimento operário pode ser considerado um movimento social de classe, isso significa que, historicamente, a acção reivindicativa da classe trabalhadora é inseparável dos objectivos políticos de longo prazo que animaram as suas lutas. Acresce que o sindicalismo foi, desde sempre, pautado pela diversidade das suas lógicas de actuação. 0 objectivo de conciliar a luta por melhorias salariais e de condições de trabalho com a missão de solidariedade internacionalista só em certas circunstâncias históricas teve algum sucesso. A penetração da doutrina marxista nos meios operários, designadamente na sequência das Internacionais Operárias, contribuiu para desenvolver uma identidade colectiva - "de classe" -, que se propunha guiar os trabalhadores e a humanidade para uma sociedade liberta de injustiças: o socialismo.

24 A velha palavra de ordem de fi nais do século XIX, "a empresa aos operários" exprimiu, desde cedo, essa utopia operária fundada na aspiração colectiva de pôr fim à exploração e à dominação social. Mas, apesar de o velho slogan do Manifesto comunista ter tido efeitos positivos na consciência internacionalista da classe trabalhadora, a grande narrativa da classe operária não passou afinal de uma mistificação. Se é verdade que em momentos extraordinários a classe operária (em concreto) se confundiu com a ideia de um hipersujeito e vanguarda da revolução socialista, também é verdade que entre o "nome" e a "coisa" nunca existiu uma real coincidência (Cabral, 1983). Entre a linguagem de classe e o fenómeno em si interpôs -se a força doutrinária do próprio discurso, que se tornou factor de construção identitária ou, pelo menos, produtor de identificações colectivas que (objetivamente) mobilizaram milhões de trabalhadores (Jones, 1989; E.P. Thompson, 1987).

No entanto, não se deve daqui concluir que o sindicalismo de há duzentos anos foi caracterizado pelo monolitismo. Pelo contrário, como acima se assinalou, desde sempre foi marcado pela dispersão e pluralidade de lógicas de ação, de formas organizativas e de referências ideológicas. Alguns teóricos clássicos do movimento sindical, como o casal S. \& B. Webb (1976), acentuaram acima de tudo a vertente economicista e funcional dos sindicatos - o chamado "sindicalismo de mercado" -, que efectivamente deu lugar às modalidades mais corporativas e institucionais do sindicalismo moderno, enquanto outras correntes colocam antes a ênfase na ideia do sindicalismo como movimento social, que assenta na conjugação de aspetos como a defesa da democracia direta, o autoempoderamento e a consciencialização perante os problemas mais amplos da classe.

o sindicalismo de movimento pode, assim, definir -se pelos seguintes traços: i) a afirmação de identidades e interesses colectivos dos trabalhadores; ii) a tensão entre a defesa dos interesses da classe trabalhadora e as lutas mais gerais contra a opressão; iii) a prioridade dada à relação 'normal' de emprego caracterizada pelos contratos de emprego permanente, onde a actividade grevista teve maior impacto; e, finalmente iv), a representação da classe trabalhadora no seu conjunto e a sua organização em bases nacionais e não internacionais (Melucci, 1996; Dibben, 2004). É claro que, mesmo entre os que se reclama de "sindicalismo combativo" ou "sindicalismo de classe" constantes polémicas e debates acompanharam a história da ação sindical. Por outro lado, foram constantes as disputas em torno das instâncias defiliação, desde a interferência de forças partidárias às pressões institucionais de todos os tipos. A própria internacionalização do campo sindical foi desde há mais de duzentos anos pautada pela controvérsia como mostram os encontros das Internacionais Operárias, de finais desse século e que definiram as principais divisões entre famílias ideológicas no campo da esquerda (social democracia, socialismo, comunismo, etc.). Acresce que tais divisões continuam presentes 
na atualidade, como prova o processo de criação e de fusão das centrais e federações sindicais na Europa e no Mundo (CESL, CSI, CSM, etc.). No caso português a própria CGTP IN tem recusado, até agora, a adesão à recém criada CSI, devido em larga medida ao passado de estreita colaboração com a CSM (estrutura herdada do campo soviético), como recentemente foi revelado por um dos seus antigos dirigentes que entrou em ruptura com a orientação dominante (Lança, 2010). Além disso, também os impactos, quer das mudanças conjunturais e estruturais, quer dos contextos locais, contribuíram para matizar a diversidade dos sindicatos.

\section{Trabalho precário}

27 As profundas transformações que têm fustigado as relações laborais no contexto da globalização neoliberal não podem deixar de fazer sentir os seus impactos no campo laboral e, consequentemente, nas formas de organização e mobilização sindical. A estagnação económica e o desequilíbrio orçamental de muitos Estados europeus conjugaram -se com as exigências de retorno ao velho mercantilismo e todo o conjunto de pressões do capital financeiro e da economia monetária, que empurraram as principais economias europeias para uma crise sem precedentes, cuja saída está ainda por vislumbrar, mas com resultados desastrosos no mundo do trabalho (Castel, 1998; Antunes, 2006; Aubenas, 2010).

Como assinalei atrás, o recuo do Estado social perante as exigências do capital especulativo arrastou consigo um preocupante declínio da classe média assalariada e empurrou amplos sectores da classe trabalhadora manual para as margens do sistema. As conquistas asseguradas pelo direito laboral e a contratação coletiva entraram em regressão, a velha indústria entrou em colapso e as políticas educativas e de qualificação do emprego não conseguem travar a avalanche de medidas claramente regressivas, que os trabalhadores e os seus sindicatos são obrigados a aceitar.

Neste cenário, é urgente refletir sobre as formas (velhas e novas) de denúncia e de ação coletiva, e tentar compreender qual poderá ser o papel dos sindicatos e dos novos movimentos de protesto laboral na travagem desta tendência. Para compreender a complexidade do fenómeno social aqui em causa, induzido a partir do campo produtivo mas que, obviamente, vai muito além de uma questão "laboral" -, vale a pena lembrar o caráter plural e heterogéneo do próprio sindicalismo. Muito embora as correntes e sensibilidades internas ao campo sindical sempre tenham sido múltiplas, convém não esquecer que foi sobretudo o "sindicalismo de movimento" que mais contribuiu para as grandes transformações ocorridas nas sociedades industriais modernas (Dibben, 2004).

Muitas das análises sociológicas centradas na questão das "políticas identitárias" vêm desde os anos oitenta chamando a atenção para a ideia de que, para lá da grande narrativa "de classe" que o marxismo ajudou a disseminar pelo mundo, sempre pontificou uma enorme variedade de condições contextuais, culturais e históricas que produziram subjetividades e identidades coletivas revestidas de forte potencial político e capacidade de ação.

31 Desde a Inglaterra do século XIX até alguns contextos sociopolíticos mais recentes - por exemplo, o 25 de Abril de 1974 em Portugal, mas também outras ondas de protesto dos sectores mais jovens e dos trabalhadores precários, como os FERVE (Fartos d'Estes Recibos Verdes), o movimento MayDay, os Precários Inflexíveis (PI) ou os Intermitentes do 
Espetáculo -, a mobilização popular não se deveu apenas a motivações materiais e a razões económicas, mas foi em boa medida impulsionada por factores de natureza cultural e identitária. E estes são sempre construídos a partir de estímulos discursivos dirigidos ao imaginário coletivo, em nome da "boa" comunidade, solidária e justa (seja ela o "povo", a "classe operária", o "socialismo" ou "o trabalho digno"), apelando a identificações estruturadas contra um adversário (ou inimigo de classe) conotado com agressões à dignidade, aos direitos humanos e sociais, à justiça social, etc. (Thompson, 1987; Savage, 2004).

As atuais condições comunicacionais, inclusive as criadas pelos novos meios de comunicação digital, lado a lado com as crescentes dificuldades de mobilização do velho paradigma de organização sindical, encontram no terreno de precariedade e de vulnerabilidade em que se encontram os novos setores proletarizados do trabalho um território fértil de penetração e de influência, sobretudo junto dos setores mais jovens e qualificados da força de trabalho.

Embora fosse precipitado, segundo a perspectiva que aqui se persegue, advogar a falência do sindicalismo - ou mesmo a sua incapacidade de responder aos problemas laborais do presente - importa considerar a hipótese de que as novas dinâmicas associativas emergentes terão um efeito palpável nas atuais estruturas sindicais, seja porque podem, a prazo, vir a miná-las por dentro, seja porque podem oferecer -se como um potencial concorrente na mobilização dos setores mais precários.

Perante a disponibilização de novos dispositivos de informação e participação, dotados, aliás, de contornos mediáticos e simbólicos capazes de minimizar o risco de exposição do trabalhador (como ocorre com o ativista sindical tradicional) é hoje possível estruturar formas de intervenção sociopolítica de novo tipo, criando redes ou cadeias de denúncia e contestação - a partir de modalidades de construção ficcionada da identidade colectiva, como, por exemplo, as chamadas cyber-identidades - passíveis de promover com sucesso a emergência de novos sujeitos de protesto e de contestação ativa. Muitas revoluções e protestos sociais ao longo da história começaram por movimentos de carácter disperso e espontâneo baseados nesse tipo de elementos (Skocpol, 1985).

Por outro lado, sabe -se como, à medida que os movimentos se vão expandindo e ganhando força, à medida que se afi rmam as suas lideranças, à medida que se estruturam as suas bases organizativas e orientações ideológicas, tende do mesmo passo a reforçar -se a componente formal e, por isso, as conquistas alcançadas pelos movimentos sociais caminham geralmente de par com o apagamento das suas lutas.

Ora, no caso dos sindicatos - em especial o velho sindicalismo operário -, sujeitos de tão diversas e profundas transformações sociais, eles foram (em particular no caso europeu) cooptados ao longo da segunda metade do século XX, revertendo -se a mobilização combativa em crescente institucionalização, burocratização. Paradoxalmente ou não, o certo é que a elevação a "parceiros de diálogo" se foi aos poucos traduzindo na crescente fragilização (tanto no que se refere à capacidade de acção coletiva quanto no que concerne aos níveis de filiação das suas bases).

No período mais recente, é sobretudo a multiplicação das formas de prestação de serviços e de condições de trabalho de características precárias que vêm acentuando a dependência e a fragilidade do sindicalismo e dos trabalhadores, em especial os segmentos mais jovens e menos qualificados (Beck, 2000; Paugam, 2000). Todavia, os problemas por que vêm passando os sindicatos nas últimas três ou quatro décadas devem 
-se também a responsabilidades que lhes são próprias. A questão da democracia interna, a resistência à renovação das lideranças e as dificuldades de manterem uma permanente ligação às bases - nomeadamente aos sectores mais frágeis, como os jovens, as mulheres, os imigrantes, e mesmo os desempregados ou em regimes de trabalho com os falsos recibos verdes - constituem alguns dos obstáculos que se colocaram à revitalização do sindicalismo.

Nos últimos anos, com o triunfo do neoliberalismo, os sindicatos tornaram -se ostensivamente alvo de sucessivos ataques por parte do poder económico e político (inclusive mesmo os governos socialistas e sociais democratas da Europa) e criou -se na esfera pública um estigma anti -sindical. Por isso, o sindicalismo se queixou, com razão, de se pretender o regresso aos tempos "satânicos" de Marx. É isso que tem vindo a ser promovido pelo capitalismo de hoje numa escala global, e cujas principais vítimas se localizam no hemisfério Sul e no continente asiático. As pressões do mercado e da economia global deixaram aos sindicatos uma estreita margem de manobra.

39 Com a intensificação da crise, o aumento do desemprego e a reestruturação da Administração Pública - leia -se flexibilização dos despedimentos, aposentação compulsiva e privatização -, cujo impacto mais visível se fez sentir, no caso português, em sectores como a educação e a saúde, nos últimos anos o sindicalismo tradicional voltou a assumir maior protagonismo, promovendo diversas passeatas e contestando ativamente muitas das políticas públicas naqueles domínios ${ }^{2}$. Em alguns dos momentos mais "quentes" da contestação sociolaboral foram novamente as estruturais tradicionais do sindicalismo português (com maior destaque para a CGTP) que dominaram a ação colectiva. Mas, como se pode facilmente compreender com a descrição de alguns dos principais movimentos e associações vocacionadas para o combate à precariedade no trabalho (adiante apresentadas), esses momentos de maior crispação contra o poder instituído (nomeadamente na área da educação), como as grandes manifestações de professores, mobilizaram conjuntamente as velhas e as novas estruturas e associações do campo laboral.

No entanto, é necessário não esquecer que o esforço de actualização por parte das estruturas sindicais tem sido diminuto e insuficiente para responder aos problemas do mundo laboral. Nas últimas décadas, enquanto a economia e os mercados deixaram de estar confinados a fronteiras, o movimento sindical revelou grandes dificuldades em agir para lá do âmbito nacional (e muitas vezes sectorial). A globalização revelou -se contraditória e gerou efeitos paradoxais, justapondo lógicas globais e locais. Expressão dessas contradições foi a onda de movimentos sociais da viragem do século que se reclamaram de "alter -globalização". Os repetidos protestos desencadeados desde a cimeira da Organização Mundial do Comércio (OMC) em Seattle, em 1999, que culminaram com os encontros do Fórum Social Mundial, em Porto Alegre e noutras cidades, os protestos da juventude francesa em 2005, da Grécia em 2008, ou mesmo as acções do movimento MayDay e dos FERVE, em Portugal, revelaram alguns aspectos inovadores e as potencialidades que podem retirar-se das novas redes do ciberactivismo que eles protagonizam (Estanque, 2009).

41 Fica, portanto, claro que as transformações sociais das últimas décadas e seus impactos no plano do emprego introduziram um maior grau de complexidade na esfera produtiva e acrescentaram dificuldades à organização sindical. Olhando para os contornos da conflitualidade ou para as atuais condições de negociação, facilmente se constata que o poder patronal tem procurado aproveitar -se da situação de crise para impor mais e mais 
reformas de viés liberal. O emprego criado e os novos contingentes de jovens universitários que entram no mercado de trabalho ocorrem em condições de extrema precariedade (Antunes, 2006).

Vem a propósito recordar que a precariedade laboral se assume no caso português sob duas modalidades principais. Os contratos a prazo (ou a termo certo) e a fórmula dos "Recibos verdes" - forma que foi popularizada para definir as situações de prestação de trabalho independente -, que abaixo será abordada. Quanto aos contratos a prazo, Portugal tem atualmente a terceira maior taxa da UE a 27 (com 22\%), a seguir à Polónia $(25,4 \%)$ e à Espanha $(25,4 \%)$. Para agravar essa situação, sabe-se que nas camadas etárias mais jovens (até aos 24 anos) mais de metade trabalha sob condições precárias, além de que são também eles os mais afectados pelo desemprego (Eurostat, 2010). Estes dados vêm reiterar a indicação de um estudo recente do Banco de Portugal, que já tinha concluído que, em cada dez empregos criados, nove são precários e raras vezes se convertem em permanentes.

\section{Novos atores sociolaborais ${ }^{3}$}

\subsection{FERVE - Fartos d'Estes Recibos Verdes}

O FERVE foi fundado em Março de 2007. Surgiu no Porto, mas a sua acção nunca se circunscreveu apenas a esta cidade. Define -se como um grupo de trabalho cuja ação se desdobra em duas vertentes: a primeira é a criação de um espaço de partilha e de denúncia de situações de trabalho que configurem a utilização indevida de «Recibos verdes $»^{4}$, acabando dessa forma com o isolamento a que estes trabalhadores se encontram votados. A segunda é a promoção de um debate alargado acerca do trabalho precário de forma a retirá-la da invisibilidade, inserindo -a no discurso social, político e mediático. Em traços gerais, este movimento pretendeu chamar a atenção para combater o carácter permanente dos "falsos recibos verdes" que, originalmente, eram vocacionados para a prestação de serviços (portanto, ocasionais ou de duração limitada) e dirigidos a trabalhadores autónomos (que não obedecem a hierarquias, estabelecem o próprio horário e possuem local de trabalho próprio) e, em particular, aos profissionais liberais. Consciencializar os trabalhadores de que se encontram submetidos a uma situação irregular e são alvo de "chantagem" com base na grave situação económica do país foi um dos principais objectivos que esteve na base das suas acções. Pretendeu -se unir diversos segmentos da força de trabalho numa "plataforma de luta alargada e unida na defesa dos direitos laborais" contra a passividade e conivência do Estado com esta situação e a impunidade daqueles que constantemente subvertem as regras. Embora os objectivos iniciais fossem modestos, o seu percurso, e a visibilidade que o grupo adquiriu, nomeadamente através da atenção que mereceram da parte dos grandes meios de comunicação de massas, ultrapassou em larga medida as expectativas colocadas pelos seus criadores.

o funcionamento deste movimento constitui um exemplo típico do chamado "ciberativismo". Os primeiros passos que deram foram a construção de um blogue e de um endereço de correio electrónico (cuja lista de contactos tem vindo a crescer significativamente) com o objectivo de proporcionar a partilha de experiências na primeira pessoa, tendo recentemente aderido ao Facebook, o que lhes permite a divulgação de informação e iniciativas, e obter respostas em tempo real. o blogue ${ }^{5}$ é a sua interface 
principal e, juntamente com a lista de contactos, tem revelado ser uma ferramenta fundamental para a mobilização em momentos chave do seu percurso ${ }^{6}$. Uma das suas grandes vantagens é a de permitir a partilha de experiências na primeira pessoa (com a possibilidade de manter o anonimato), ao mesmo tempo que contribui para a construção de um espírito de grupo. A leitura dos testemunhos e relatos publicados permitem uma identificação em torno do seu principal traço de união: o vínculo contratual precário. Mesmo não existindo uma partilha directa de experiência profissional, esta permuta cruzada de vivências ajuda sem dúvida à consciencialização individual e colectiva acerca da realidade profissional em que se encontram inseridos. Este tipo de expedientes, apesar de ocorrerem numa zona por assim dizer "privada", ou de construção de subjectividades fictícias, mais até do que através da via presencial, contribuem para que a opinião individual ganhe solidez. Se é verdade que não é na intimidade de cada um que se forjam as revoluções, o certo é que, no século XXI, a revolução digital permite que, no silêncio do quarto de cada um, todas as inibições, complexos e estigmas sejam esbatidos. E é isso que estimula as pulsões de liberdade e de partilha que irradiam através do ciberespaço. Assim, a identificação com o grupo atenua o sentimento de isolamento do trabalhador e estimula a tomada de consciência de que ele não é um caso isolado, antes se insere num quadro mais alargado de ilegalidade e injustiça social. Trata -se de uma espécie de identidade fi ccionada e "hiperreal", que pode ter consequências práticas inquestionáveis e um forte impacto sociopolítico na esfera politica (Ribeiro, 2000; Waterman, 2002).

45 A relação que o movimento mantém com os media foi e é muito importante. Aquando da sua fundação, o FERVE enviou um comunicado para a Agência Lusa que motivou reacções imediatas, entre as quais o contacto da RTP para a realização de uma reportagem sobre a matéria. A reacção da comunicação social foi surpreendente e rapidamente passaram de um cenário de não reconhecimento (em que eram questionados sobre a seriedade do movimento) para uma atitude de respeito pela actividade desenvolvida. Com regularidade passou a ser solicitada a sua cooperação para a realização de reportagens e artigos sobre precariedade laboral por parte da comunicação social nacional e também internacional. Esta cooperação com a imprensa e o audiovisual tem-se revelado extremamente importante para a missão de dar visibilidade à realidade dos "falsos" recibos verdes. Como já mostraram os movimentos estudantis como o maio de 68, a comunicação social é uma das maiores "armas politicas" do nosso tempo, e saber usá-la é uma preocupação que acompanha as iniciativas do FERVE, pois, através desses meios, o poder político, as instituições públicas ou mesmo as empresas são muitas vezes pressionados e obrigados a recuar nas suas posições. As peças televisivas e reportagens em que a porta -voz do movimento é entrevistada são cada vez mais frequentes, o que é ilustrativo da projecção que adquiriram.

O FERVE marcou presença no Protesto Geral de 29 de Maio de 2010 convocado pela CGTP. Na sequência do Plenário Nacional de Sindicatos a 15 de Maio foi anunciada a realização de uma Grande Manifestação Nacional no dia 29 de Maio em Lisboa, que pretendeu, simultaneamente, ser e construir um momento alto da contestação às políticas introduzidas pelo governo e consideradas injustas e violentas, e exigir um novo rumo para o país em que os trabalhadores estejam no centro das prioridades bem como da acção política. $\mathrm{O}$ acontecimento foi assinalado pela presença plural de inúmeras organizações da sociedade civil, desde partidos políticos, sindicatos a outros movimentos de cariz mais informal. 


\subsection{O MayDay}

47 O MayDay pretende promover a consagração do dia 1 de maio como um dia de acção contra a precariedade laboral. Tal como o indica o significado da expressão (pedido de socorro, de ajuda, ou, mais concretamente, é a formulação de um pedido internacional de ajuda face aos efeitos da globalização neoliberal), tem por objectivo chamar a atenção para esta questão e expressar o descontentamento de todos aqueles que se sentem afectados pelas situações de precariedade tais como a imigração ilegal, o trabalho em regime clandestino, o tráfico internacional de mão-de-obra, etc., cujo impacto e denúncias se vêm repetindo no território europeu. Celebra-se no dia 1 de maio e é promovido na tentativa de actualizar o Dia do Trabalhador.

Os protestos promovidos por este movimento são sobretudo dirigidos ao poder político, que acusam de uma atitude passiva e permissiva perante estes problemas, e resulta do ativismo de uma rede de grupos feministas, anti-capitalistas e contra a precariedade laboral que se vem expandindo na Europa. Para além dos movimentos que se encontram na base do processo, o MayDay acolhe a participação de todos aqueles que quiserem dar um contributo, reunindo um conjunto de pessoas bastante heterogéneo ${ }^{7}$. A criação desta rede transeuropeia encontra-se profundamente enraizada na acção dos movimentos anti -globalização, e baseia-se na ideia de que a luta anti-capitalista deve ultrapassar o âmbito restrito do sindicalismo e da luta pelos direitos dos trabalhadores, abrangendo outras questões que se prendem com a "mercantilização da vida".

O MayDay não se restringe, porém, à participação na parada no dia 1 de maio em cada ano. É, simultaneamente, um ponto de encontro e de partida. Não se trata de um acontecimento por si só, mas antes de um processo de mobilização contínuo que, de ano para ano, se expande e diversifica. Este processo, que culmina na realização da parada, desenrola-se durante os meses que a antecedem (normalmente inicia -se em Fevereiro), envolve a realização de acções de divulgação - debates, demonstrações públicas criativas, distribuição de flyers, venda de artigos de propaganda para angariar fundos, etc. - e a realização de assembleias de carácter público em que, em conjunto, são tomadas todas as decisões relativas às acções $\mathrm{e}$ ao curso que o processo de mobilização segue. $\mathrm{O} \mathrm{c}$ iberactivismo é, também neste caso, um elemento fundamental à dinâmica e à forma como se processa a mobilização, já que envolve milhares de pessoas em diferentes cidades de diversos países. Sem a utilização em massa das novas tecnologias de informação seria praticamente impossível sincronizar as acções dos diferentes grupos envolvidos.

50 A primeira parada MayDay ocorreu em Milão em 2001, estendeu -se a Barcelona em $2004 \mathrm{e}$ a várias cidades por toda a Europa em 2005 formando -se a partir desse momento a rede EuroMayDay. Estima -se que o número de participantes aumentou de 5.000 pessoas em Milão em 2001 para 50.000 em 2003, e 100.000 em 2004 (Milão e Barcelona juntos). Em 2005, cerca de 200.000 pessoas participaram em manifestações e acções EuroMayDay, principalmente na Europa Ocidental. Em 2006, apesar de alguns grupos terem desistido do processo, o número de cidades participantes cresceu ao ponto de as paradas MayDay envolverem cerca de 300.000 pessoas no conjunto das vinte cidades Europeias aderentes.

51 A criação do MayDay surgiu na sequência do Movimento Anti-Globalização, que consideraram a insuficiência do Fórum Social Europeu. As suas acções, na vertente específica de combate à precariedade, remontam a 2000 e têm como marco as greves dos trabalhadores part -time da Pizza Hut e do McDonald's que ocorreram no Inverno desse 
ano. Estas mobilizações deram origem à primeira rede direcionada para o combate à precariedade em solo europeu - a Stop Précarité. Esta tem ligações com a AC! (Agir contre le Chômage), CGT (Confédération Général du Travail), SUD, CNT (Confederación Nacional del Trabajo), Trotskystes e com outros elementos da esquerda radical francesa. Apesar desse momento "fundador", as suas raízes podem ser seguidas até ao fi nal dos anos 1990, altura em que começam a ser organizadas as Marchas Europeias contra o desemprego, a precariedade e as exclusões (Marches européennes contre le chômage, la précarité et les exclusions). Tratou -se de uma plataforma de associações que fundaram uma rede europeia que procurou resistir à tendências dominantes e lançar uma contra-ofensiva aos avanços do neoliberalismo. Como resultado, em 1997 foi organizada a primeira marcha, que juntou 500 pessoas em Amesterdão numa manifestação por um Tratado da União Europeia mais justo que o Tratado de Amesterdão.

52 A partir desse momento sucedem -se as manifestações nas grandes cidades europeias, normalmente por altura das edições do Fórum Social Europeu, em que as reivindicações feitas giram em torno de uma Europa Social mais justa. Para além dos referidos, outros movimentos têm desempenhado um papel central na organização do MayDay a nível europeu. Destacam -se os Intermittents (França) e os Chainworkers (Itália). Ambos apresentam grandes semelhanças com movimentos que operam em Portugal, podendo por isso falar-se da existência de um "embrião" de acção colectiva comum.

\subsection{Precários Inflexíveis (PI)}

Os Precários Inflexíveis (PI) surgiram na sequência da primeira experiência do MayDay em Lisboa, em 2007. Do colectivo que se juntou com o objectivo de mobilizar os trabalhadores precários nasceram os PI. A sua constituição serve o objectivo de dar continuidade ao trabalho realizado no âmbito do MayDay em 2007 e pretendeu dar resposta ao vazio existente no que diz respeito a grupos que se propusessem suscitar a discussão em torno da precariedade e a empreender acções para combatê-la. Propunham -se a "trilhar" um caminho semelhante ao FERVE (que os precedeu em escassos meses), optando, no entanto, por um enfoque mais alargado e voltado para as múltiplas faces da precariedade. Actuam preferencialmente na região de Lisboa, muito embora participem em iniciativas por todo o país.

Mais uma vez, as plataformas e redes informáticas presidiram ao nascimento deste movimento. O blogue dos $\mathrm{PI}^{8}$ foi o primeiro ponto de contacto com a sociedade civil e desempenha um papel central na dinamização de todas as suas acções. Ficou online em 18 de Julho de 2007 e no primeiro post o Manifesto Precário9 definem -se como "precários no emprego e na vida", denunciam a presença da precariedade em todos os sectores - desde o privado à administração pública - e a invisibilidade a que se encontram votados. Segundo o texto inicial, pretendem "reinventar a luta", o que significa que na génese da sua formação está o facto de as formas tradicionais (referindo -se às estratégias sindicais) carecerem de adequação ao contexto actual. As palavras de ordem são apelativas e reveladoras da sua determinação para combaterem a situação - "precários sim, mas inflexíveis". Também este grupo segue tendências de grupos europeus, orientados para exaltar as experiências de auto -organização de trabalhadores. A sua motivação advém do sentimento de marginalização decorrente das políticas governamentais que, em nome da modernização e enquanto medidas para fazer face à grave crise económica em curso, conduzem ao agravamento da precarização do trabalho. 
55 À semelhança do que acontece com os FERVE, as acções iniciais dos PI centram-se quase exclusivamente na divulgação e denúncia de situações de injustiça social e de ilegalidade. Os conteúdos presentes no blogue variam entre a publicação de informação divulgada nos órgãos de comunicação social (notícias de jornais, peças televisivas e reportagens transmitidas nas rádios), testemunhos de "vidas precárias", artigos de opinião escritos por cidadãos comuns e vídeos que registam as acções do movimento. A inclusão de posts com vídeos de acções na estrutura do blogue é uma estratégia destinada a mobilizar pessoas externas ao movimento. Todas as convocatórias para assembleias e para a realização de aç̧ões públicas são também publicadas no blogue de forma a obter uma divulgação mais ampla e a captar novos participantes.

Os PI empreendem com grande regularidade acções "de rua" e o contacto "cara a cara" é visto como essencial. Consideram que a dimensão do contacto directo não deve ser menosprezada apesar da internet constituir uma ferramenta fundamental para a sua estratégia. A facilidade em realizarem "acções de rua" prende-se com a existência de um "núcleo duro" que se tem mantido estável desde a sua formação.

\section{Conclusão: sindicatos versus movimentos}

57 Apesar do sindicalismo apenas tímida e pontualmente se ter envolvido em iniciativas conjuntas com estes grupos, o actual contexto apresenta-se propício a novos desafios, quer para o (velho) movimento sindical quer para os novos movimentos sociais. Diversos autores e académicos têm realçado a necessidade de se criarem novas alianças e dinâmicas internacionalistas, como condição para revitalizar o sindicalismo perante as preocupantes desigualdades e injustiças que se acentuam em todos os continentes, alegando que a globalização do capital exige respostas igualmente globalizadas ou transnacionais por parte das suas vítimas, isto é, os sectores mais dependentes e precários que as fracções emergentes da (nova) classe capitalista transnacional produzem, como se fossem "detritos" da (boa) globalização ou da "nova economia" (Sklair, 2001; Waterman, 2002; Estanque, 2007).

Embora as situações de precariedade remetam cada vez mais para problemas de contornos semelhantes à condição de hiperexploração do proletariado da era da Revolução Industrial, é pouco provável que o movimento sindical (tal como o conhecemos na Europa) consiga, por sua própria iniciativa, adaptar-se ao tempo presente e acompanhar as novas tendências de contestação dinamizadas pelos grupos e movimentos que aqui foram referidos.

A ausência de uma doutrina congregadora e de uma "utopia realista" ou "plausível" (como foi o socialismo até às primeiras décadas do século $\mathrm{XX}$ ), aliada à perda de credibilidade do marxismo como ideologia revolucionária (perante o drástico falhanço do modelo soviético), deixaram "órfãos" muitos dos dirigentes do sindicalismo e do campo da esquerda, enquanto outros foram abertamente "canibalizados" pelo sistema e aderiram a ele, com maior ou menor entusiasmo.

As actuais redes de activismo transnacional só poderão fortalecer-se em aliança com um sindicalismo de novo tipo - um sindicalismo de movimento social global - orientado para a intervenção cidadã, que se estenda para além da esfera laboral; que passe das solidariedades nacionais para as transnacionais, de dentro para fora, dos países avançados para os países pobres; que não abdique da defesa dos valores democráticos, 
mas em que estes se alarguem à democracia participativa (nas empresas, escolas, cidades, comunidades, etc); que coloque as questões ambientais e a defesa dos consumidores, dos saberes e tradições culturais locais no centro das suas lutas e negociações; que resista ao capitalismo destrutivo através de um maior controlo do processo produtivo, dos circuitos de comercialização, dos investimentos e da inovação tecnológica; que negoceie e "imponha" as suas propostas no campo das políticas de formação e qualificação profissional; que pense os problemas laborais no quadro mais vasto da sociedade, da cultura ao consumo, do trabalho ao lazer, da empresa à família, do local ao global; que recoloque o trabalho - com todas as suas metamorfoses - no centro de um novo "contrato social" ou no ponto de partida para novas ações emancipatórias (Estanque, 2004 e 2009; Antunes, 2006).

$61 \mathrm{Na}$ verdade, esse é o tipo de sindicalismo que ainda não temos. Ele pressupõe uma estratégia ambiciosa que rompa com a prática de acomodação ao funcionamento burocrático em que o velho modelo sindical se deixou enredar.

Tal combate exigiria uma reflexão mais profunda e uma atitude auto-crítica da parte das actuais lideranças e quadros sindicais. A questão é saber se os dirigentes formados no velho modelo nacional -industrial - sobretudo aqueles que devem mais obediência ao comité central de um partido do que aos trabalhadores que representam -, poderão vir a responder positivamente a estes desafios, abrindo espaço a uma verdadeira renovação, ou se deixarão definhar num sindicalismo já em acelerado processo de descredibilização.

Procurou-se com este texto estabelecer uma conexão entre o crescimento da precariedade e a fragmentação do trabalho, por um lado, e o surgimento de novos sinais de resposta e de rebeldia perante tais tendências. Por sua vez, as mutações no campo laboral revestem -se de profundas consequências no campo sindical, colocando os velhos sindicatos frente a frente com uma realidade que lhes exige capacidade inventiva e renovadora.

64 A discussão que aqui se procurou desenvolver pressupõe a existência de uma estreita ligação entre o lado informal do trabalho e da economia e as condições com que os trabalhadores e suas formas de organização conseguem (ou não) responder coletivamente às dificuldades de uma classe que, além de fragmentada e em recuo, sofre agora com a intensificação da sua dependência. Na verdade, o trabalhador precário não apenas continua a ser o elo dependente e incapaz de negociar individualmente os seus direitos pelo menos os seu segmentos mais precários - como é nas atuais condições colocado nos subterrâneos da informalidade e da ilegalidade. Além de oprimido e explorado, o trabalhador perdeu a sua voz e a sua visibilidade enquanto classe. Teremos de aguardar para saber se será capaz de voltar a erguer -se contra as novas injustiças.

\section{BIBLIOGRAFIA}

ANTUNES, Ricardo (2006) (Org.), Riqueza e Miséria do Trabalho no Brasil. São Paulo: Boi Tempo.

AUBENAS, Florence (2010), Le Quai de Ouistreham. Paris: L' Olivier. 
BECK, Ulrich (2000), Un nuevo mundo feliz: la precaridad del trabajo en la era de la globalización. Barcelona: Paidós.

CABRAL, M. Villaverde e outros (orgs.) (2003), Desigualdades Sociais e Percepções da Justiça. Lisboa: ICS.

CARMO, Renato Miguel do (org.) (2010), Desigualdades Sociais. Estudos e Indicadores. Lisboa: Observatório das Desigualdades/ Editora Mundos Sociais.

CASTEL, Robert (1998), As Metamorfoses da Questão Social. Petrópolis: Editora Vozes.

DIBBEN, Pauline (2004) “Social movement unionism”, in Harcourt, Mark \& Geoffrey Wood (eds.), Trade Unions and Democracy. Manchester: Manchester University Press, p. 280 -392.

ESTANQUE, Elísio (2000), Entre a Fábrica e a Comunidade: subjectividades e práticas e de classe no operariado do calçado. Porto: Afrontamento.

ESTANQUE, Elísio (2004), “A Reinvenção do sindicalismo e os novos desafi os emancipatórios: do despotismo local à mobilização global”, in Boaventura S. Santos (org.), Trabalhar o Mundo: os caminhos do novo internacionalismo operário. Porto: Afrontamento, pp. 297 -334.

ESTANQUE, Elísio (2007), “A questão social e a democracia no início do século XXI”, Finisterra Revista de Reflexão Crítica, vol. 55/56/57, pp. 77 -99.

ESTANQUE, Elísio (2009), “Precariedade, sindicalismo e acção colectiva”, in FERVE e APRE, Dois Anos a FERVEr, - retratos da luta, balanço da precariedade. Porto: Afrontamento/FERVE/ APRE, pp. 97 -101 .

EUROSTAT (2010), Relatório “Labour Force Survey”, de 04/08/2010.

FERREIRA, António Casimiro (2009), Da Sociedade Precária à Sociedade Digna: balanço da evolução social em Portugal 2003 -2008. Coimbra: CES, Relatório Preliminar.

GONÇALVES, Carlos Manuel (2010) “Emprego dos licenciados universitários”, in Carmo, Renato Miguel do (org.) Desigualdades Sociais 2010. Estudos e Indicadores. Lisboa: Observatório das Desigualdades/ Editora Mundos Sociais, pp. 181 -190.

JONES, Gareth Stedman (1989), Languages of Class. Studies in English working class history 1832-1982. Cambridge: Cambridge University Press.

FONSECA, Dora (2010), Dossier movimentos de trabalhadores precários em Portugal e rede MayDay. Coimbra: FEUC/CES, working paper.

LANÇA, Florival (2010), Inter Nacional. Lisboa: Profedições.

LOUÇÃ, Francisco e CALDAS, José Maria Castro (2009), Economia(S). Porto: Afrontamento.

MELUCCI, Alberto (1996), Challenging Codes. Collective Action In The Information Age. Cambridge: Cambridge University Press.

PAUGAM, Serge (2000), Le Salarié de la Précarité. Paris: Puf.

REIS, José (2009), Ensaios de Economia Impura. Coimbra: CES/Almedina.

RIBEIRO, Gustavo Lins (2000) "Política Cibercultural: ativismo político à distância na comunidade transnacional imaginada-virtual”, in S. Alverez, E. Dagnino e A. Escobar, Cultura e Política nos Movimentos Sociais Latino -Americanos. Belo Horizonte: Editora UFMG, pp. 465 -502.

SAVAGE, Mike (2004), "Classe e história do trabalho", in Batalha, Claudio, et al., Culturas de Classe. Campinas, SP: Editora da Unicamp, pp. $25-48$. 
SILVA, Manuel Carvalho da (2009), Trabalho e Sindicalismo em Tempo de Globalização. Lisboa: Círculo de Leitores, Temas e Debates.

SKLAIR, Leslie (2001), The Transnational Capitalist Class. Oxford/ Malden, Ma: Blackwell.

SKOCPOL, Theda (1985), Estados e Revoluções Sociais. Lisboa: Editorial Presença.

STIGLITZ, Joseph (2004), Rumo a um Novo Paradigma. São Paulo: Francis.

THOMPSON, E. P. (1987) A Formação da Classe Operária Inglesa. Rio de Janeiro: Paz e Terra.

TILLY, Charles (1978), From Mobilization to Revolution. Addison/Mass: Wesley Publishing Company.

WATERMAN, Peter (2002), “O internacionalismo sindical na era de Seattle”, Revista Crítica de

Ciências Sociais, 62. Coimbra; CES, p. 33 -68.

(in Dora Fonseca, "Dossier movimentos de trabalhadores precários em Portugal e rede MayDay". Coimbra: FEUC/CES, 2010, working paper).

ABIC, disponível em: http://www.abic -online.org [consultado em:23 -01 -2012]

Fartos destes recibos verdes, disponível em: http://fartosdestesrecibosverdes.blogspot.com [consultado em: 23 -01 -2012]

Intermitentes, disponível em: http://intermitentes.blogspot.com/[consultado em: 23 -01 -2012]

Precários inflexíveis, disponível em: http://www.precariosinfl exiveis.org/[consultado em: 23

$-01--2012]$

Libcom, disponível em: http://libcom.org/library/middlesex -declaration -precariat [consultado em:23 -01 -2012]

Mayday Lisboa, disponível em: http://www.maydaylisboa.net/[consultado em: 23 -01 -2012]

Mayday Coimbra, disponível em: http://maydaycoimbra.blogspot.com/[consultado em: 23

$-01--2012]$

Mayday Porto, disponível em: http://maydayporto.blogspot.com/http://

maydaycoimbra.blogspot.com/[consultado em: 23 -01 -2012]

Mayday Lisboa 2009, disponível em: http://maydaylisboa2009.blogspot.com/[consultado em:23

$-01-2012]$

Mayday Lisboa, disponível em: http://maydaylisboa.blogspot.com/[consultado em: 23 -01 -2012]

Mayday Lisboa, disponível em: http://2007mayday.wordpress.com/[consultado em: 23 -01 -2012]

Euromayday, disponível em: http://www.euromayday.org [consultado em: 23 -01 -2012]

AC, disponível em: http://www.ac.eu.org/[consultado em: 23 -01 -2012]

Chainworkers, disponível em: http://chainworkers.org/[consultado em: 23 -01 -2012]

Confidencial, disponível em: http://rrhh -confidencial.blogspot.com/[consultado em: 23 -01 -2012]

EuroMayday, disponível em: http://be.euromayday.eu/2007/index.html [consultado em: 23 -01--2012]

EuroMayday, disponível em: http://www.euromayday.org/[consultado em: 23 -01 -2012]

Genaration Precaire, disponível em: http://www.generation -precaire.org/[consultado em: 23 -01-2012]

Il manifesto, disponível em: http://mir.it/servizi/ilmanifesto/call/[consultado em: 23 -01 -2012] 
Sindominio, disponível em: http://www.sindominio.net/karakola/precarias.htm

http://telekemados.blogspot.com/[consultado em: 23 -01 -2012]

\section{NOTAS}

1. Que, diga -se, passou a ser conhecida desde o passado dia 12 de Março de 2011 como a "Geração à Rasca", devido à enorme manifestação convocada por um grupo de jovens em situação precária, através do Facebook, e que, segundo vários analistas, terá marcado um momento de viragem nas modalidades de ação colectiva e afirmado um novo fenómeno no cenário político nacional (voltarei a este assunto na parte final).

2. Tendo, em alguns casos, contribuído fortemente para mudanças políticas, como aconteceu com a substituição da ex-ministra da educação Maria de Lurdes Rodrigues, que no segundo governo Sócrates cedeu o lugar a Isabel Alçada, personificando um estilo e uma postura completamente diferentes da anterior ministra que tinha sido um constante foco de polémica e de protesto por parte dos sindicatos deste sector. 0 que de resto também já acontecera, anos antes, com o antigo ministro da Saúde (Correia de Campos), embora neste caso contassem sobretudo os protestos das populações locais onde as infraestruturas como serviços de urgência e outras unidades de saúde de cidades do interior estavam a ser ameaçadas de encerramento.

3. Este tópico foi elaborado a partir de um Dossiê de autoria de Dora Fonseca (2010). Além dos grupos aqui referidos foram ainda identificados neste documento mais algumas estruturas com características semelhantes, tais como: Plataforma dos Intermitentes do Espectáculo e do Audiovisual (PIEA); APRE! (Activistas Precários); Maldita Arquitectura.

4. Desde o início dos anos oitenta foi regulamentado o estatuto do "Trabalhador independente", que, como o nome indica, se refere a um "recibo" (devidamente registrado nas finanças). Embora o regime de recibo verde fosse concebido para trabalhos pontuais, em Portugal começou a generalizar -se o recurso a esse tipo de prestação, desde os anos 80, como forma de contornar o direito do trabalho e facilitar o despedimento. Daí surgiram os chamados "falsos recibos verdes", isto é, situações em que o mesmo trabalhador permanecia trabalhando para a mesma entidade (e poupando os encargos às empresas) durante anos. Formalmente essa situação ilegal verifica-se sempre que o trabalhador obedece a uma hierarquia dentro da empresa, cumpre um horário de trabalho por esta estipulado, exerce a atividade nas instalações da empresa e usa as ferramentas de trabalho fornecidas pela mesma. Este expediente, juntamente com os contratos a prazo, contribuiu para aumentar o volume de assalariados em situação de trabalho precário.

5. http://fartosdestesrecibosverdes.blogspot.com

6. São destacados dois momentos em que estas ferramentas foram essenciais: a petição para ser entregue na Assembleia da República, solicitando a neutralização dos "falsos" recibos verdes, foi fundamentalmente divulgada através do blogue e da lista de contactos, podia ser descarregada a partir destes, impressa e posteriormente enviada para um apartado criado para o efeito ou então subscrita online (dessa forma foram conseguidas 5257 assinaturas válidas); na sequência das multas emitidas em Dezembro de 2008 pelo MFAP (Ministério das Finanças e Administração Pública), a posição do FERVE e a divulgação que fez da matéria através destes dois meios esteve na origem de uma onda de protestos que levou o Governo a recuar (as multas foram anuladas e o prazo da entrega do anexo em falta da referida declaração foi alargado).

7. Os grupos que fazem parte da rede EuroMayDay encontram -se disseminados por toda a Europa e estão presentes nas seguintes cidades: Amesterdão, Barcelona, Berlim, Bremen, Copenhaga, Den Bosch, Estocolmo, Genebra, Gent, Gornja Radgona, Hamburgo, Hanau, Helsínquia, L'Aquila, León, Liége, Lisboa, Londres, Ljubljana, Málaga, Maribor, Marselha, Milão, Nápoles, Palermo, Porto, Sevilha, Terrassa, Tubingen, Viena e Zurique. A partir de 2006, a rede estendeu -se para além do 
território europeu e passou a marcar presença em Tóquio (a primeira cidade "extra -europeia"), Fuchu, Fukuoka, Quioto, Machida, Sapporo, Sendai, Toronto e Tsukuba.

8. http://www.precariosinfl exiveis.org/

9. É um manifesto de apelo à acção, de forma a quebrar o silêncio sobre a questão e para que sejam tomadas medidas concretas. É dirigido a todos aqueles que de alguma forma vêem a sua vida ser afectada pela precariedade laboral.

\section{RESUMOS}

A atual tendência de precarização das relações de trabalho, na Europa e no mundo, de dissociação entre condições profissionais e vínculos laborais, está a pôr em causa os velhos critérios e formas de diálogo, os valores de solidariedade e no fundo o "contrato social" inspirado pela filosofia iluminista e consolidado desde o pós -II Guerra Mundial, sob o modelo de Estado-Providência. Nos últimos vinte anos, as transformações ocorridas do mercado de trabalho fustigaram de forma dramática os direitos e a qualidade do emprego, conduzindo a uma imparável desagregação do sistema produtivo que até aos anos oitenta do século passado pôde sustentar uma classe média que parecia em expansão e alimentar os sonhos individuais de muitos trabalhadores. 0 aumento e a diversificação da precariedade laboral passou a constituir um dos principais traços de recomposição do mercado de trabalho tanto em Portugal como nos outros países da União Europeia. É neste quadro que importa discutir o legado do movimento sindical e interpelar a sua capacidade de adaptação a esta nova realidade. Para tal, o presente artigo procura interpretar o significado das novas formas de ação coletiva e movimentos "inorgânicos" que têm surgido nos últimos tempos, revelando novas linguagens, modalidades de mobilização e de ativismo cívico e político, procurando responder à crescente fragilização do mundo do trabalho e desafi ando os hábitos e as formas organizativas das velhas estruturas sindicais.

The current trend of de-structuring industrial relations in Europe is leading to new forms of labour and expanding precariousness at work, as well as undermining the old criteria and forms of dialogue, working conditions, and values of solidarity. This process is threatening the old "social contract" model, inspired by Enlightenment philosophy and has been consolidated since the post-World War II under the form of welfare state. Over the last twenty years deep changes have occurred in the world of work and labour relations which have dramatically lashed the rights and quality of employment, leading to a breakdown of the former productive system which has been feeding middle-class expectations and the expansion of individual dreams (of socially upward mobility) of thousands of workers. The growth and diversification of job insecurity has become one of the main traits of decomposition of the labour market both in Portugal and in other European Union countries. It is in this context that it is important to discuss the legacy of the labour movement and question its ability to adapt to this new reality. To this end, this paper analyses the significance of new forms of collective action and "inorganic" movements that have emerged in recent times, revealing new languages, forms of mobilization and political activism, seeking to respond to the increasing fragility of the world of labour and challenging old trade union habits, organizational forms

La tendance actuelle de précarisation des relations de travail en Europe et dans le monde et la dissociation entre les conditions et les liens professionnels menacent les anciens critères et les 
formes de dialogue, les valeurs de solidarité et, en somme, le modèle de contrat social inspiré par la philosophie illuministe et consolidé depuis la seconde guerre mondiale sous la forme d'État providence. Au cours des vingt dernières années, les changements survenus dans le marché du travail ont porté atteinte d'une forme dramatique aux droits et à la qualité de l'emploi, ce qui a conduit à une désagrégation du système productif. Jusqu'aux années quatre-vingt du siècle dernier, celui-ci a pu faire vivre une classe moyenne qui semblait être en expansion et a alimenté les rêves individuels de nombreux travailleurs. L'augmentation et la diversification de la précarité de l'emploi sont devenues l'un des principaux aspects de la recomposition du marché du travail au Portugal et dans d'autres pays de l'Union européenne. C'est dans ce contexte que doit être discuté l'héritage du mouvement ouvrier et que nous devons nous demander quelle est sa capacité d'adaptation à la nouvelle réalité d'aujourd'hui. Ce texte essaye donc d'interpréter la signification des nouvelles formes d'action collective et des mouvements " inorganiques » qui sont apparues ces derniers temps et qui révèlent de nouveaux discours, des nouvelles formes de mobilisation et d'activisme civique et politique, cherchant à répondre à la fragilité croissante du syndicalisme et bouleversant les habitudes et les formes d'organisation des anciennes structures

ÍNDICE

Mots-clés: précarité, syndicalisme, mouvements sociaux, travail

Palavras-chave: precariedade, sindicalismo, movimentos sociais, trabalho

Keywords: precariousness, trade unionism, social movements, labour relations

\section{AUTOR}

\section{ELÍSIO ESTANQUE}

Investigador do Centro de Estudos Sociais e Professor da Faculdade de Economia da Universidade de Coimbra, elisio.estanque@gmail.com 